\title{
Research progress of building insulation materials at home and abroad
}

\author{
Danzhen $\mathrm{Wu}^{\mathrm{a}}$, Weili Gu and Sigui $\mathrm{Li}$ \\ HVAC, Institute of urban construction, University of South China, China
}

\begin{abstract}
In general, the thermal insulating material is that thermal coefficient is less than or equal to $0.14 \mathrm{~W} /(\mathrm{m} \cdot \mathrm{K})$, with good heat preservation performance and is widely used in the field of industrial and construction. This paper introduced the main kinds of thermal insulation material, summarized the research progress of thermal insulation materials, introduced the application in building and the research status of the organic heat preservation material, inorganic heat preservation material and composite insulation materials , pointed out that along with the research of thermal insulation material unceasing deepening, the performances of thermal preservation material will continue to improve and be perfect, and make bigger contribution to building energy efficiency.
\end{abstract}

Keywords: thermal insulation materials; environmental pollution; greenhouse effect; type.

\section{Introduction}

The thermal insulation material is a kind of material or composite that slows down the rate of heat transfer by conduction, convection and radiation. Due to the high heat resistance, the thermal insulation material block the heat flow in and out of the building. From the perspective of environmental benefits, in the process of use thermal insulation material does not produce harmful substances, such as formaldehyde and aromatic hydrocarbons, and the product has a variety of functions, Such as antibacterial, mildew, heat insulation, fire retardant, sound insulation and antistatic etc, can reduce the use of other indoor environment improve machinery equipment, thus saving the energy, and the amount of the pollutant gas discharged by the equipment is reduced correspondingly. From the perspective of the comfort, the thermal insulation material can help reduce the indoor temperature volatility, especially during the changes of season, they can balance the indoor temperature even more. And thermal insulation materials are generally sound insulation, reducing outside noise interference. From the perspective of protecting buildings, drastic changes in temperature will damage the structure of the building, using a thermal insulation material can keep the change of temperature stable, prolonging the service life of buildings. At the same time, the use and installation of insulation materials can help to prevent the heat and flame, reducing the occurrence of fire, which can reduce casualties and property losses. There are many different kinds of insulation materials and they are widely used. Then, the article will focus on the commonly used organic heat preservation material, inorganic heat preservation material and composite insulation material, introduces the applications and research progress of them.

${ }^{a}$ Corresponding author: 1161149904@qq.com 


\section{Characteristics of thermal insulation materials}

Thermal insulation material is generally divided into three categories: organic heat preservation materials, inorganic heat preservation materials, composite type of insulating material. Organic heat preservation material is usually with polymer or polymer as the main raw materials, and add various chemical additives by certain processes to make it, with the features of light weight, good processability, high compactness, good insulation effect, but having the drawbacks of not resistant to aging, large deformation coefficient, poor stability, poor security, easy combustion, ecological environmental protection is poor, difficult construction, engineering cost is higher, its resources are limited and is difficult to be recycled. Organic building insulation materials mainly include three types, respectively is polystyrene foam (PS), phenolic foam, polyurethane foam (PUF). In addition, it also includes polyethylene foam, urea formaldehyde foam plastic and so on. Inorganic heat preservation material is a new type of heat preservation and energy saving insulation material used in the internal and external walls of buildings, Lightweight thermal insulation particles with inorganic class as lightweight aggregate, add by cementitious materials, crack additives and other fillers consisting of dry powder mortar, with excellent properties of energy saving and recycling, thermal insulation, fire prevention and anti-freezing, anti-aging and low prices and so on, and have a wide range of market demand. Such as aerogel blanket, glass wool, rockwool, expanded perlite, obdurate perlite, and so on. Composite thermal insulation material is a new type of thermal insulation material in recent years, it is produced by the use of raw materials as prevent the radiation absorbing materials, rock wool, crop straw even can use has excellent thermal insulation performance and a harmless treatment of waste, and through foaming to produce hollow materials. Composite materials have many advantages, such as fire retardant, deformation coefficient is small, good thermal insulation performance, strong aging resistance, strong durability, construction difficulty is small, low cost, wide source of raw materials, low energy consumption in the process of production, in line with the requirements of ecological and environmental protection, and can achieve the recycling of resources.

\section{Types of thermal insulation materials}

\subsection{Organic thermal insulation materials}

\subsubsection{Polystyrene foam plastics}

Polystyrene resin is the main raw material of polystyrene foam plastics, at present, according to the different production methods there are two widely used material, molded polystyrene foam (EPS) and extruded polystyrene foam (XPS), and the physical and chemical properties of them are not the same. The bibulous rate of EPS is larger than the XPS, acid and alkali resistance is better, and has a certain degree of flexibility. EPS expansion polyphenyl plate thin plastering exterior wall external thermal insulation system is a common external wall insulation system, with excellent thermal insulating properties, good waterproof performance and wind resistance, impact resistance, can effectively solve the wall cracks and water seepage. Anti-impact performance can effectively solve the wall cracks and water seepage. The system technology is mature, convenient construction, highly cost effective, and it's thermal insulation energy-saving building design and construction units commonly used insulation system [1]. Recently, the domestic research on EPS mainly concentrated on adding flame retardant nanotechnology processing, design of polymer molecular weight, select a specific proportion of foaming agent and screening can regulate the forces between molecules of the polymer additives, to increase the fire rating of EPS to B1 level[2].XPS based on polystyrene (PS) resin as raw material to the continuity of the closed-cell foam of rigid foam plastic, With advantages of high pressure resistance, low bibulous rate, moisture-proof, airtight, light quality, corrosion resistance, compared to no degradation, low thermal conductivity excellent performance. Compared with EPS polystyrene foamed plastic board, its strength, heat preservation, moisture permeability and other performance has 
improved greatly, and widely used in the dry wall heat preservation, plane concrete roof and steel structure roof insulation, low temperature storage ground, low temperature floor radiation heating, parking platform, airport runway, highway in areas such as moisture-proof insulation and control ground frost heave, it is the construction inexpensive and delicate quality of insulation, moistureproof materials [3]. But production XPS foam used foaming agent mainly for HCFC222 and HCFC2142b. The two kinds of foaming agent is that Deplete the ozone layer material, is also a strong greenhouse gas. Therefore, in the XPS foam industry is faced with enormous pressure of environmental protection. EPS/XPS plate also exists the shortage of the used temperature should not exceed $75{ }^{\circ} \mathrm{C}$, low oxygen index, and in case of fire burns easily, so people in the fire retardant treatment do a lot of research work $[1,4]$.

\subsubsection{Phenolic foam plastics}

Phenolic foam is known as the king of the heat preservation. Used as building energy-saving insulation materials, it has low thermal conductivity, good thermal insulation effect as well as the advantages of non-combustible and fire prevention, waterproof and breathable, good bonding, large rigidity, high peel strength, weather resistance and good chemical stability, non-toxic, harmless, without excitant $[5,6]$. In terms of the application status, ventilation pipe produced by the product has the characteristics of adiabatic and durable, lightweight and energy-saving, clean and beautiful, waterproof and fireproof, simple and labor-saving. The performance indicators are in line with the industry and the relevant national standards and specification requirements. Since the 90's of last century, Hongkong has imported a large number of phenolic materials from the United Kingdom for more than 100 buildings' central air-conditioning wind pipe insulation. Beijing, Shanghai and other big cities has also used the products in the HVAC system of public facilities. Therefore, Liu Wei [7] analysis that using phenolic foam as building exterior wall insulation materials can achieve the "double insurance" effect of safety and energy saving.

At present, used as closed and control the fire of building exterior wall thermal insulation materials, phenolic foam materials have been widely used in abroad. Marseille, France, Lyon and other cities built many large apartments, which had already installed the phenolic foam board in outer wall, and then coated with protective layer to prevent the fire burning spread. The government of Japanese had issued regulations about the phenolic foam that used as the standard of public buildings fire retardant materials. In our country, although the thermal insulation air duct system produced by phenolic foam has used in the water cube, the subway and other high-grade public buildings, it is still seldom used due to the less of related norms using phenolic foam as building exterior wall thermal insulation materials [8]. To further improve the environmental protection, non-toxic, phenolic foam insulation materials without the destruction of atmospheric ozone layer Freon has been researched [9]. The modification of phenolic foam can effectively solve the problems such as brittleness, easy pulverization and so on. Adding fiber modification improves the peel strength of the phenolic foam, and its brittleness has also been improved [10]. Using epoxy resin modified phenolic foam can improve the flexibility and toughness, but epoxy resin viscosity is too large. Thus the foaming process operating is difficult [11]. With polyether modified, its compressive strength can be enhanced [12].Modified by polyurethane, the impact strength and compressive strength, toughness, degree of pulverization, flexibility, etc. can be improved [13-16].

\subsubsection{Polyurethane foam plastics}

The main raw material of polyurethane foam is polymer polyol and isocyanic acid, and it's a kind of polymer foam thermal insulation material prepared by the catalytic activity of other chemical additives. According to the different foaming, it is divided into hard and soft polyurethane foam, while rigid polyurethane foam has particularly good insulation performance of insulation. The internal structure is closed pore structure, and the hole is not connected with each other, so it has good waterproof, and can be used as thermal insulation waterproof material for roofs and walls. This 
material can be formed in advance and on-site spraying molding with convenient operation, but its costs is relatively higher compared to other heat preservation material. The PU Rigid Foam oxygen index without flame retardant treatment is only $17 \%$. It gives off a lot of toxic gases such as CO2, $\mathrm{HCN}$ in the process of combustion [17]. Used as building insulation materials, once on fire, it may bring much difficulties for escape and outfire .So many scholars have studied the Pu of flame retardant [18-21]. ALi Rza Tarakclar studied the expansion of flame retardant system consisted by ammonium polyphosphate (APP), pentaerythritol (PER) powder on the application of the rigid foam. of the expansion flame retardant, the comprehensive performance of rigid foam is best . M. hirumal et al. [22] filled the rigid PU foam plastics with aluminum hydroxide and triphenyl phosphate used as composite flame retardant. When the mass ratio of aluminum hydroxide and phosphoric was $5: 1$, the hard foam oxygen index (OI) reached maximum value (29.5\%). The study found that [23-25] chemical modification of montmorillonite has a significant effect on the burning performance of polyurethane, such as halogen flame-retardant, organic phosphorus series inflaming retarding, organic flame retardant with boron, nitrogen based flame retardant and so on besides swelling flame retardant.

In addition, because the bending degree and the degree of impact of rigid polyurethane foam and other technical indicators still cannot meet the use requirement, thus in many occasions it still cannot fully meet the requirements of engineering. So people had done a lot of researches to the enhancement. The basic ideas of traditional foam plastics modification do not alter the structure of polymer, adding appropriate amount of additives in the whole system. The main methods are fiber reinforced, enhancement of particles, interpenetrating polymer network, blend and copolymerization modified et al.[26].In the fiber enhancement, Ba Zhixin[27] used the milled glass of $10-15 \mathrm{~m}$ in diameter fiber without alkali to reinforce polyurethane rigid foam discovering that compressive strength increases with the refinement of the particle size of glass fiber, while the effect is better coupling with glass fiber. The glass fiber reinforced with structural strength and fiber reinforced. Andrzej et al. [28] has made with linen and jute fabric reinforced polyurethane matrix composite materials with uniform pore structure, found that the increased fiber can lead to shear modulus and impact strength of the rise, but the increase of micropore volume in the matrix will lead to the decline in performance. In particulate reinforced side, the hollow glass beads are the common materials of reinforced rigid polyurethane. Wang Fuling [29] found that adding surface treatment such as 10 to 100 microns in diameter of glass beads can increase the bubble hole density, decrease the diameter, which has better enhancement effect in a certain range of material. Yin Bo [30] found that adding Nylon-1010 powder can improve the compression, tensile and impact strength of rigid polyurethane foam, 5\% for critical additive volume. Zhao Bin, etc. [31] used nylon 66 fiber and $\mathrm{SiO} 2$ particles as mixed strengthening agent, which can make the foam tensile, compression, impact strength improved obviously. In terms of interpenetrating network copolymers enhanced, isocyanate and epoxy resin, phenolic resin, or other prepolymer blending aggregated again after foaming can obtain interpenetrating networks copolymer obviously increase the mechanics performance of material, $\mathrm{Hu}$ Yun li, etc [32] have studied the mechanical properties of rigid interpenetrating polymer network of polyurethane/epoxy resin, found that the system strength rise with the increase of epoxy resin content.

\subsubsection{Urea formaldehyde foam plastics}

Urea formaldehyde (UF) plastic, commonly known as "electric jade", is made by urea and formaldehyde as raw materials, though condensation polymerization reaction to obtain urea formaldehyde resin, adding fillers, colorants, lubricants, plasticizers and other materials processed into pressure plastic powder, then through heating and mould pressing to be products .It has high surface hardness and certain mechanical strength. It is uneasy to deformation, but the brittleness is big. It is odorless, tasteless, strong tinting strength, and the shape like a beautiful jade; good heat resistance, uneasy to burn; acid and alkali resistance, poor water resistance, good electrical insulation .

In China, urea formaldehyde resin are mainly used in construction, light industry and textile industry, of which the amount of wood industry accounted for about two thirds, and they mainly used in wood adhesive and preparing hot pressing plywood, and the rest for packaging, vehicle manufacturing. In addition, urea formaldehyde resin can also be used for leather processing, inorganic 
fiber bonding, casting workshop of sand core bonding, graphite resistor and plaster reinforced, foam structure and ion exchange resin. Although with less dosage, It fully reflects the performance of urea formaldehyde resin of widely used.

Although the application of organic materials is very extensive, these traditional materials has some defects more or less, cannot meet the needs of modern industry and life. The heat resistance of EPS, XPS, PU and other organic materials is poor, easy to burn, and the combustion will release a lot of heat, producing large amounts of toxic gas, which not only accelerated the spread of the fire, but easy to cause the trapped personnel and rescue personnel casualties. Therefore, these materials on the exterior wall of the building insulation technology application subject to certain restrictions, in foreign developed countries have explicitly restricted or prohibit the use. The density of PF is big, the overall strength is poor, and molding conditions requirements is high, foaming difficult, less amount of injection molding equipment for imports from abroad at high prices. At present, it is difficult to form a commercial production. UF has poor water resistance and water absorption, the material in the process of drying and hardening is likely to produce cracks, and in the contact surface of the material and the spatial prone to arise loose phenomenon, the using process will release formaldehyde, cannot be widely popularized. Therefore, the development of inorganic exterior wall thermal insulation material will be an indisputable choice of future building insulation materials.

\subsection{Inorganic thermal insulation material}

\subsubsection{Aerogel blanket}

Aerogel blanket on nano silica aerogels as the main material, through a special process with glass fiber cotton or preoxidation fiber mat of composite flexible insulation mat, is currently about $400{ }^{\circ} \mathrm{C}$ temperature of minimum thermal conductivity of solid insulating materials. Its characteristic is low thermal conductivity, tensile and compressive strength to a certain extent, with water repellent and fire resistance, and it is convenient to be used in thermal insulation construction, belong to a new type of insulation material. Aerogel blanket has the features of soft, easy to cut, small density, inorganic fire prevention, the overall hydrophobic, green environmental protection, which can replace the glass fiber products, asbestos insulation mat, silicate fiber products and other traditional flexible insulation material which are not environmental protection and good thermal insulation performance. Aerogel blanket is mainly used for industrial pipelines and storage tanks, industrial furnace body, power plants, lifesaving cabin, warships bulkhead, EMU, buried pipe, injection molding machine, detachable insulating sleeve, heavy oil exploitation of high temperature steam pipe, transportation, household appliances, steel, nonferrous metal, glass and other fields of thermal insulation.

\subsubsection{Glass wool}

Glass wool belongs to a category of glass fiber and is a kind of artificial inorganic fibers. Using quartz sand, limestone, dolomite and other natural ore as the main raw material, with some soda, borax and other chemical raw materials melting into glass. In the melt state, with the aid of outside force blow flocculent formats to jilt into fine fibers, fiber and fiber for interchanges between, intertwined together, presents many small gap, and the gap can be seen as pore. Therefore, glass wool can be regarded as porous materials, with good thermal insulation, sound absorption performance, which has good shape, small volume density, slow thermal conductivity, corrosion resistance, and stable chemical performance. At present, the production technology of glass wool with flame spray blowing method, due to the environmental protection degree is low, the unit energy consumption is high, and the slag ball content is high, which has been phased out and instead of the output of a single machine is high, energy consumption is low and no slag ball centrifugal spinning method production process. Glass wool products have more varieties, mainly include glass wool felt, glass wool board, glass wool belt, glass wool blanket and glass wool insulation pipe, widely used in residence, central air conditioning system, the steel structure workshop, household electrical appliances, railway carriage, sound barrier 
and many other areas, greatly changed people's life. Lack of the scale of application and development of glass wool products, glass wool products specifications only dozens of, the application scope is very narrow. With more than $80 \%$ of the international applications in the field of architecture compared, the domestic glass wool in the field of construction is larger gap.

\subsubsection{Rock wool}

Rock wool is as main raw material with the selection of basalt and dolomite, adding a certain amount of auxiliary material, after 1450 DEG $\mathrm{C}$ high temperature above melting and adopting the international advanced four axis high- speed centrifugal centrifuge fibrous loose materials, rock wool fiber after adding an appropriate amount of adhesive, dustproof agent, water repellent admixture and other admixtures, by laminating roller pressing, curing oven curing process, can get all kinds of series of rock wool products, rock wool can be made according to different uses: blanket, bar, pipe, granular, plate and so on. Rock wool products with good thermal insulation, cold insulation, sound absorption and stable chemical properties, and has the characteristic of non-flammable, high hate water rate and low moisture absorption rate. Therefore, the rock wool is widely used in petroleum, electric power, construction, metallurgy, textile, national defense, transportation and other industries. Since the beginning of this century, as a result of the external wall thermal insulation material selection improper, cause the fire disaster is shocking, and to the safety of people's lives and property caused great losses, rock wool products with its excellent fire insulation properties is internationally recognized as the main energy-saving materials in the "fifth" conventional energy sources. On the building, peruse 1 ton rock wool products for thermal insulation and a year at least can save equivalent to $1 \mathrm{~m}$ tons of oil energy, in line with low carbon, energy saving, emission reduction trend, so the rock wool as the ideal building insulation materials, is facing unprecedented development opportunities and challenges. But at the same time, rock wool as fiber insulation materials, water absorption rate is high, products easy bibulous and resulting in the coefficient of thermal conductivity increases sharply, and lose the heat preservation and heat insulation performance, therefore, reduce the bibulous rate of rock wool is very important. In Europe, rock wool as the insulation materials used in external wall insulation accounted for only thermal insulation materials market of about $20 \%$, the reason is that high quality requirements of rock wool in the external wall thermal insulation, and it's expensive. In addition, rock wool as exterior wall thermal insulation materials on the construction procedures and quality assurance measures strictly, in the rainy season and winter construction restricted.

\subsubsection{Expanded perlite}

Expanded perlite is perlite ore after preheating and instantaneous high temperature baking expansion made of an internal honeycomb structure of white granular materials. Under the room temperature thermal conductivity coefficient is 0.0245 to $0.048 \mathrm{~W} /(\mathrm{m} \cdot \mathrm{K})$, high-temperature thermal conductivity coefficient is 0.058 to $0.175 \mathrm{~W} /(\mathrm{m})$, low-temperature thermal conductivity coefficient is 0.028 to $0.038 \mathrm{~W} /(\mathrm{M})$, the highest use temperature is $800 \mathrm{DEG} \mathrm{C}$, used as efficient thermal insulation, cold insulation filling materials. Also,can use for filtering agent, catalyst, molecular sieve and the carrier of rubber, fertiliser, pesticide. Expanded perlite has excellent physical and chemical properties of light weight, no toxicity, good insulation performance, Corrosion resistance, non-combustible, and the characteristic low cost, at the same time with the heat preservation heat insulation and sound absorption and so on multiple special performance, widely used in construction, metallurgy, petroleum, machinery, light industry, hydropower, casting, medicine, food, agriculture, forestry, horticulture and other departments. Expanded perlite used for building insulation materials in Europe accounted for $50 \%$ of perlite usage, in North America accounted for $60 \%, 55 \%$ in Japan, $65 \%$ in China. But the expansion perlite bibulous rate is high, the water resistance poor leads to thermal insulation mortar in the stirring volume shrinkage deformation largely, and products in the late insulation performance lower, easy to crack, and grass-roots level bonding strength is low prone to hollowing. At the same time, in the process of mixing, transportation and parking, expanded perlite thermal insulation mortar is easy to appear stratified, segregation and bleeding site, construction 
performance is poor and influence the technology performance of the insulation mortar after hardening. Also, due to the expanded perlite insulation materials more than the combination of perlite and cement, there is a contradiction between the strength and thermal conductivity is difficult to solve. These give it as building insulation materials brought a fatal flaw.

In summary, inorganic insulation material products is mainly composed of natural minerals, easily available raw materials, stable physical and chemical properties, low toxic or non-toxic, nonflammable, high-temperature resistant, no volatilization, no pollution, and all materials can be recycled, does not cause secondary pollution, is a kind of environmental protection green building materials. Although aerogel blanket in the domestic preparation process has become complete, but it is lightweight, soft, does not apply to many fields. Glass wool, rock wool are bibulous rate is high, under the condition of normal temperature thermal performance is not stable, etc; expanded perlite, bibulous rate is high, poor thermal performance and its widely application is restricted.

\subsection{Composite silicate thermal insulation materials}

Composite silicate thermal insulation material is a kind of solid substrate connection closed mouth hole mesh structural material. This product is a kind of use special non-metallic mineral as base material, mixed with a certain amount of auxiliary materials and filling material with certain chemical additives, adopt the new process and new technology developed. The product has a low thermal conductivity coefficient, the heat loss is small, the material thickness, and non-toxic, no pollution to the environment, no corrosion to equipment, is a kind of new high efficiency, light weight, hightemperature insulation materials, and it is the domestic currently most ideal insulation material. Compare with the traditional insulation materials and general insulation materials, coordination for high-temperature performance and heat insulation performance of two interacting matter. Also has the advantages of convenient operation, no stimulation, no dust pollution, arbitrary cut volume, transportation and installation without loss, etc., widely used in petroleum, chemical, electric, metallurgy, national defense and other industries, it is the ideal material for heat preservation and heat insulation, high temperature resistance, energy conservation of thermal tank, pipeline and other equipment. Composite silicate products mainly kinds are magnesium silicate, aluminum silicate, rare earth composite insulation materials, etc. And in recent years the emergence of sepiolite heat preservation and heat insulation material as the leader of composite silicate insulation materials, due to its good thermal insulation heat insulation performance and the application effect, has attached great importance to the construction industry, and show strong market competitiveness and broad market prospect [33-35].

Aluminum silicate refractory fiber as high-temperature heat insulation material and refractory material has a long history, in recent years, this kind of material as insulation materials were used for preparation of new thin ceramic fiber composite insulation layer, and win a widely use in aerospace field, especially in the insulation parts where requirements to the quality of light and space are limited, this material has been the most effective use, achieve the ideal thermal protection effect, so it is getting more and more attention. With aluminium silicate as basic materials of the ceramic fibre can be made into various forms of products, such as fiber mat, mat, fiber board, fiber paper, fiber rope and all kinds of fabric, etc [36]. At present, many countries have carried out the Research and application of aluminum silicate fiber. The United States, the former Soviet Union, Japan and the United Kingdom in a leading position, especially that the United States has developed many new varieties. The silicon carbide company (Carborundum) in the United States has produced a thickness to $0.8 \mathrm{~mm}$ of aluminium silicate fibre paper, this kind of fibre paper with the characteristics of light weight, small thermal conductivity and resistance, etc. In the field of Aeronautics and Astronautics, aluminum silicate fiber composite materials has been used as a heat insulation layer of rocket engine components, lining of ignition device, insulation layer of oxygen generator and so on, in the military and commercial aircraft for the leading edge of the wing, the end of the head cap ablative protection layer, the exhaust channel thermal protection layer and all kinds of instruments and equipment on the plane of fire protection layer, etc [37]. 


\section{The development trend of building insulation materials}

Building thermal insulation materials in our country after several decades of development has been more and more mature. However, there is a great gap compared with international advanced level. At present, the building thermal insulation materials are developing towards high performance, multifunction composite and environmental friendly. For example, the solid waste recycled of ceramic industry is developing, Shui Anze[38] use the waste of polished tile, high temperature sand, low temperature sand and various kinds of clay as raw material, after the ball mill, drying, forming, sintering, developed a new lightweight building material with closed pores and heat insulation function. In terms of comprehensive utilization of fly ash on the thermal power industry, Zhengzhou University professor Yang jiu-jun [39] separated thick walls cenospheres from fly ash of which size is greater than $44 \mathrm{um}$ and its apparent density is greater than $1.0 \mathrm{~g} / \mathrm{cm} 3$ as raw material, by adding appropriate amount of high alumina cement and aggregate aluminum as adhesives, produced no burned fly-ash beads insulation brick, which has characteristics of low thermal conductivity, low heat permanent line rate, good thermal shock resistance, being used as a thermal insulation material of thermal furnace, reducing the cost of the thermal insulation products.

In addition, in order to improve the quality of modern industry and life, the research was constantly improved in all aspects for the performance of original material. For example, in the aspect of flame retardant, polystyrene (PS) and polyurethane (PU) material has excellent performance, but there is a disadvantages that the oxygen index is low and in the flame burning. Therefore, many experts and scholars constantly devoted to research improvement. Nowadays, the pattern of the system development has already been formed with the ontology flame retardant, halogen flame retardant, phosphorous flame retardant, flame retardant, clay expansion. For example, the flame retardant ontology of polystyrene (PS), was introduced in PS chain with flame retardant effect of nitrogen, phosphorus, and halogen element to product PS can overcome the weaknesses of adding flame retardant to the PS led to the decrease of the material mechanical properties, flame retardant infiltrate, cluster, volatilization, and volatilization, decomposition failure in the process of machining [40].Again for instance, graphite expansion flame retardant system of polyurethane foam system, Shilei et al. [41] investigated the influence of different size of EG on the microstructure of RPUF and combustion performance. The results of investigate showed that the compatibility of EG and PU structure is poorer. When the particle size of EG was greater as flame retardant, the flame retardant plastic would be better and the LOI value could reach $39.5 \%$. In terms of strength, the brittleness of phenolic foam plastic and urea formaldehyde foam is large, and the strength of the polyurethane foam is not enough, which needed to increase its toughness. With plus fiber, polyurethane and epoxy resin modified, all can improve the brittleness of phenolic foam and improved its deflection and toughness. Through fiber reinforced and interpenetrating polymer network, blending and copolymerization modified, the strength of the polyurethane foam was improved. Urea formaldehyde foam plastics were not yet in terms of increasing strength get big progress. In reducing the bibulous rate, the bibulous rate of rock wool and expanded perlite is very high and influence the insulation material in the same time. We might start from its composition and production process to reduce their bibulous rate. Of course, these remained to be further study of experts and scholars.

\section{Conclusion}

At present, due to the required performances of thermal insulation materials are constantly improved, therefore, the research and development of building insulation materials is very rapid in recent years. There are many different kinds of building insulation materials and their performances also have their own advantages and disadvantages. From the perspective of reducing building energy consumption and improving construction safety, the development of high strength, moisture-proof, noncombustible, environmentally friendly energy-saving construction materials will be the main direction of research and development, the results of the study is bound to be widely used. 


\section{References}

1. XianCheng Hao, XiaoLing Zhan, TingJie Li.The study of expansion polyphenyl plate thin plastering exterior wall thermal insulation system construction process [J].Energy Saving in Buildings, (3): 36 (2007).

2. ZongHu Zhao. Discussion on building exterior wall thermal insulation material [J]. Safety \& Security Technology, (4):43-44. (2011)

3. Yong Wang. The extruded polystyrene (XPS) foam industry status quo and development trend of China [J]. China Plastics, 24 (4):12-16. (2010)

4. Hao Zhang, JianJie Wei, Xueling Zhou.EPS external thermal insulation technology in the application of the construction energy-saving transformation [J]. Journal of Pingyuan University, 21 (5) (2004)

5. FeiFei Bi.Simple analysis of external thermal insulation technology and energy-saving new materials [J]. Forestry Science and Technology Information, 43 (2):48-49. (2011)

6. Jie Su, YingYing Yu. Phenolic insulation materials application in building energy saving [J]. Science \& Technology Information, (15):282-283. (2009)

7. Wei Liu. Security, economic, green new building materials -The application status application and market prospects of phenolic foam [C]/2009 national new wall insulation materials and new technology new products and construction application technology exchange conference papers, (2009).

8. Chao Ji, XuanYuan Qiu, ShiKai Zhan. The external wall insulation fire and phenolic foam [J]. Shanghai Building Materials, (5):24. (2009)

9. ErJun Tang, BaoYong Tian, GeHong Zhang, et al. Development of a new type of non toxic and non combustible phenolic foam plastics [J]. New Building Materials, (6):39-41 (2002)

10. Shen H B, Lavoie A J, Nutt S R.Enhanced peel resistance of fiber reinforced phenolic foams [J] .Composite: Part A: Applied Science and Manufacturing, 34:941-948 (2003)

11. DongPing Qiao, WeiMin Li, ShuPing Wang, et al. Study on the toughening of phenolic foam plastics by flexible epoxy resin [J]. Henan Chemical Industry, (23):22-23. (2006)

12. Dongbiao Ge, ShuZhong Wang, Fuzeng Hu. Study on phenolic resin and its foam toughened by polyether [J]. Fiber Reinforced Plastics/Composite, (6):22-27 (2003)

13. Ruili Qian, FengFu Chen. Polyurethane modified phenolic foam plastics [J]. Liaoning Chemical Industry, (6):18-20 (1994)

14. ChunHua Zhou, Wei Liu, ZhuBai Xie,et al. Toughening modification of phenolic resin foam plastics[J]. Journal of Jinan University(Journal of Shandong Institute of Building Materials), 18 (3): 243-245 (2004)

15. Jue Cheng, MingLi Liang, GuangTai Jin. Study of the brittleness of phenolic foam polyurethane prepolymer[J].China Plastics Industry, 32 (1) (2004)

16. Liang $\mathrm{Xu}$, ZhenGuang Wen, Jue Cheng. Preparation of A two-component system foam Polyurethane / phenolic resin [J]. Journal of Beijing University of Chemical Technology (Natural Science Edition), 37 (3): 59-63. (3):73-77 (2010)

17. DaFei Zhong. Application of polyurethane in building exterior wall thermal insulation material (J). Polyurethane (12):62 (2007)

18. YongJun Chen, Bin Li, Lan Liu, et al. Research progress of flame retardant rigid polyurethane foam plastics (J). Plastic Science and Technology, 40 (3):103 (2012)

19. JinFeng Cui, Yongliang Liu, Junhong Guo et al. Research status and development trend of flame retardant polyurethane foam (J). China Building Materials Science \& Technology, 21 (1):68 (2012)

20. JinPing Wang, JingHui Chen. Application of flame retardant polyurethane foam in the construction field (J). Fire Technique and Products Information, (3):57 (2011)

21. Ali Rza Tarakclar .The effects of intumescent flame retardant including ammonium polyphosphate/pentaerythritol and fly ash fillers on the physicomechanical properties of rigid polyurethane foams(J).J Appl Polym Sci, 120:2095 (2011) 
22. Thirumal M,Nikhil K Singha,Dipak Khastgir,et al.Halogen-free flame-retardant rigid polyurethane foams:Effect of alumina trihydrate and triphenylphosphate on the properties of polyurethane foams(J).J Appl Polym Sci, 116:2260 (2010)

23. Xu Z B,Kong $\mathrm{W}$ W,Zhou M X,et al.Effect of surface modification of montmorillonite on the properties of rigid polyurethane foam composites(J).Chin J Polym Sci, 28(4):615 (2010)

24. Nihal Sarier,Emel Onder.Organic modification of montmorillonite with low molecular weight polyethylene glycols and its use in polyurethane nanocomposite foams $(\mathrm{J})$.Thermochim Acta, 510:113 (2010)

25. $\mathrm{Ru} \mathrm{Li}$, Jun Zhang. Study on polyurethane / montmorillonite composite flame retardant rigid foam materials [J]. China Plastics. 19 (8):21 (2005)

26. TieMin Liu, Guangcheng Zhang, Ting Chen, et al. Research progress on high performance foam plastics [J]. Engineering Plastics Application, 34 (1):61-65 (2006)

27. ZhiXin Ba, YuMing Dai, Zhangzhong Wang. Mechanical properties of milled glass fiber reinforced rigid polyurethane foam [J]. Development and Application of Materials, 20 (6):17-20 (2005)

28. Andrzej K Bledzki, Zhang Wenyang, Andris Chate. Natural-fiber- reinforced polyurethane microfoams [J]. Composites Science and Technology, 61: 2405-2411. (2001)

29. Fuling Wang, Qilin Mei, ZhiXiong Huang. Study on the properties of hollow glass bead reinforced rigid polyurethane foam materials [J]. Science and Technology of Overseas Building Materials, 26 (6):1-3 (2005)

30. Bo Yin, Hui Quan, ZhongMing Li, et al. The morphology and mechanical properties of rigid polyurethane foam filled with powdered nylon 1010 [J]. Polymeric Materials Science \& Engineering, 20 (5) 151-154158 (2004)

31. Bin Zhao, ZhenGuo Yang, JianHua Wang, et al. Preparation and microstructure of fiber and particle hybrid reinforced rigid polyurethane foam $[\mathrm{J}]$. Polymeric Materials Science \& Engineering, 21 (1):188 190,194 (2005)

32. Yunli $\mathrm{Hu}$, Chuanpin Zou, Xing Su, et al. Study on the mechanical properties of polyurethane / epoxy resin interpenetrating network polymer rigid foam [J]. Polyurethane Industry, 21 (6):18-21 (2006)

33. ZhiJian Sun, Wei Sun, Jialin Fu, et al. The status and development trend of thermal insulating materials in China (J). Energy Engineering, (4):26 (2001)

34. Zhizhong Xu, ShuangMei Cao, Hong Guo. Discussion of research and development prospect of building energy saving technology in China (J). Industrial Construction, (4):73 (2004)

35. Qi Yang. Application and development of building energy conservation materials in China (J). Journal of Panzhihua University, (3):84 (2007)

36. Ailian Tong, YuPing Jiang. New high purity ceramic fiber composite material and its application (J). AEROSPACE MATERIALS \& TECHNOLOGY, (1):14 (1995)

37. Wen Ni, FengMei Liu. Principle and preparation of super thermal insulation material of nano pore (J). New Building Materials, (1): 36 (2002)

38. AnZe Shui, HaiBin Xia, LingKe Zeng. Using of polishing brick waste of preparation porous thermal insulation building material (J). Bulletin of the Chinese Ceramic Society, 27 (1) (2008)

39. JiuJun Yang, HongJiang Wu. Study on the thermal insulating bricks of no burn fly ash beads (J). Refractories, 40 (3):210 (2006)

40. ZiQiang Lei, Wei Wang, Zhe Zhang. Research progress of flame retardant polystyrene (J). Plastic Science and Technology, 39 (4):93 (2009)

41. Lei Shi, ChunRong Tian, QiuMing Zhou, et al. A study on the flame retardant and high density rigid polyurethane foam with different particle sizes of expandable graphite (J). China Plastics, 20 (4) (2006) 